\title{
Temperature Effects on Retention and Separation of PAHs in Reversed-Phase Liquid Chromatography Using Columns Packed with Fully Porous and Core-Shell Particles
}

\author{
Christophe Waterlot $^{1}$ and Anaïs Goulas ${ }^{1,2}$ \\ ${ }^{1}$ Laboratoire Génie Civil et géo-Environnement (LGCgE), ISA Lille, 48 boulevard Vauban, 59046 Lille Cedex, France \\ ${ }^{2}$ Université Lille 2 Droit et Santé, Faculté des Sciences Pharmaceutiques et Biologiques, 3 rue du Professeur Laguesse, \\ 59006 Lille Cedex, France
}

Correspondence should be addressed to Christophe Waterlot; christophe.waterlot@isa-lille.fr

Received 25 November 2015; Revised 23 February 2016; Accepted 3 March 2016

Academic Editor: Victor David

Copyright (C) 2016 C. Waterlot and A. Goulas. This is an open access article distributed under the Creative Commons Attribution License, which permits unrestricted use, distribution, and reproduction in any medium, provided the original work is properly cited.

\begin{abstract}
Effects of temperature on the reversed-phase chromatographic behavior of PAHs were investigated on three columns. The first was the recent $\mathrm{C}_{18}$ column $(250 \mathrm{~mm} \times 4.6 \mathrm{~mm})$ packed with $5 \mu \mathrm{m}$ core-shell particles while the others were more conventional $\mathrm{C}_{18}$ columns $(250 \mathrm{~mm} \times 4.6 \mathrm{~mm})$ packed with fully porous particles. Among the $16 \mathrm{PAHs}$ studied, special attention has been paid to two pairs of PAHs, fluorene/acenaphthene and chrysene/benzo[a]anthracene, which often present coeluting problems. Due to the low surface area of the core-shell particles, lowest retention time of each PAH was highlighted and effects of the temperature on the separation of PAHs were negligible in regard to those using columns packed with fully porous particles. For each PAH studied, it was demonstrated that peaks were symmetrical and may be considered as Gaussian peaks when the column packed with core-shell particle was employed. In the best condition, the separation of PAHs was conducted at $16^{\circ} \mathrm{C}$ under very low pressure values (670-950 psi $=46-65$ bars). Depending on PAHs, the limit of detection ranged from 0.88 to $9.16 \mu \mathrm{g} \mathrm{L}^{-1}$. Analysis of spiked acetonitrile samples with PAHs at 10 and $50 \mu \mathrm{g} \mathrm{L}^{-1}$ and tap water at $10 \mu \mathrm{g} \mathrm{L} \mathrm{L}^{-1}$ gave very good recoveries $(94 \%-109.3 \%)$ and high precision $(1.1 \%-3.5 \%)$.
\end{abstract}

\section{Introduction}

Laboratory experiments have shown that the genotoxic, mutagenic, and carcinogenic activity depended on the chemical structure of polycyclic aromatic hydrocarbons (PAHs) [1]. As a consequence, 16 PAHs have been included in the list of priority pollutants by the US Environmental Protection Agency (US EPA) [2]. These PAHs are usually analyzed by gas chromatography coupled to mass spectrometry [3-8] and less frequently by liquid chromatography coupled to mass spectrometry [9-11]. Cheaper alternative methods consist in using liquid chromatography coupled to diode array (DAD) or fluorescence detectors $[3,8,11-14]$. Most of separation of PAHs using LC is carried out using columns packed with the octadecyl group bonded type silica gel $\left(\mathrm{C}_{18}\right)$. This reversedphase LC column is the most commonly used for the analysis of PAHs because of the high theoretical plate number, the high repeatability, and the quality of their separation due to the more hydrophobic property than the columns packed with silica particles covalently bonded with octyl groups. Many studies reported that the efficiency in the separation of PAHs depended on the chain length of the stationary phase but also on chemically bonded octadecylsilyl phases [1517]. On the other hand, the solute selectivity is influenced by the density of alkyl chains on the silica surface and/or the temperature or the stationary phase. In the last case, the mobility of the alkyl chain decreases with the temperature, resulting in a more ordered arrangement of them on the silica surface with a similar morphology as a crystalline solid [1820].

In the last decades, the analytical performances of the reversed-phase columns were improved with new technologies, especially combining column packed with particles of sub- $2 \mu \mathrm{m}$ order with ultrahigh pressure liquid 
chromatography (UHPLC) system for which high backpressure values are obtained [21-26]. Among these technologies, pellicular and then fused-core particles were used at high operating pressures without degradation of their performance with time while using high mobile phase velocities [25-27]. In the 1990s, a second generation of columns appeared (Poroshell 300 from Agilent) and separation of large molecules like proteins was improved in comparison with columns packed with fully porous particles [28]. The modern core-shell particles like Halo (Advanced Materials Technology, USA) and Poroshell 120 (Agilent), named the third generation, were manufactured by fusing porous silica layer onto the solid silica particles in order to limit the time solute molecules spend inside the particles [25, 29], improving the kinetics of the separation process. Many studies showed that columns packed with the $2.6 \mu \mathrm{m}$ and then $1.7 \mu \mathrm{m}$ core-shell particles exhibited excellent performance [21, 23, 25]. The stationary phase particles of these columns are composed of a solid silica core surrounded by a homogeneous and durable porous layer, allowing better efficiencies and faster analyses than totally porous particles of the same size. This performance improvement is likely due to the package quality of the core-shell columns for which the eddy diffusion terms of these columns are significantly smaller $(-40 \%)$ than that of the column packed with fully porous particles [21-25, $30]$. However, the use of these types of column, especially those packed with sub- $2 \mu \mathrm{m}$ particle size, needs an ultrahigh pressure system (UHPLC). Columns with larger diameter shell particles have been so recently commercialized in order to conduct analyses with low pressure systems. Among these columns, the recent packed with the $5 \mu \mathrm{m}$ core-shell particles were tested in the separation of the 16 PAHs recommended by the US EPA with the following main objectives: (i) the study of the retention with temperature, (ii) the characterization of peaks for each $\mathrm{PAH}$, (iii) the determination of detection and quantification limits and the precision on the analytical method, and (iv) the validation of the method using spiked tap water samples.

\section{Materials and Methods}

2.1. Chemicals and Reagents. Separation and detection of PAHs were developed with individual standards (SigmaAldrich, Saint-Quentin Fallavier, France) or standard solution of mixed PAHs (EPA-610 Oekanal, SigmaAldrich) for which name and concentration are given hereafter: naphthalene (Naph; $10.4 \mathrm{mg} \mathrm{L}^{-1}$ ), acenaphthylene (Acy; $9.9 \mathrm{mg} \mathrm{L}^{-1}$ ), fluorene (Flu; $10.0 \mathrm{mg} \mathrm{L}^{-1}$ ), acenaphthene (Ace; $9.7 \mathrm{mg} \mathrm{L}^{-1}$ ), phenanthrene (Phe; $10.2 \mathrm{mg} \mathrm{L}^{-1}$ ), anthracene (Anth; $10.2 \mathrm{mg} \mathrm{L}^{-1}$ ), fluoranthene (Fluo; $9.9 \mathrm{mg} \mathrm{L}^{-1}$ ), pyrene (Pyr; $9.7 \mathrm{mg} \mathrm{L}^{-1}$ ), chrysene (Chr; $10.0 \mathrm{mg} \mathrm{L}^{-1}$ ), benzo[a] anthracene $\left(\mathrm{BaA} ; 10.3 \mathrm{mg} \mathrm{L}^{-1}\right)$, benzo[b]fluoranthene $\left(\mathrm{BbF} ; 10.0 \mathrm{mg} \mathrm{L}^{-1}\right)$, benzo[k]fluoranthene (BkF; $9.9 \mathrm{mg} \mathrm{L}^{-1}$ ), benzo[a]pyrene (BaP; $\left.9.9 \mathrm{mg} \mathrm{L}^{-1}\right)$, dibenz[a,h]anthracene (DiAn; $10.1 \mathrm{mg} \mathrm{L}^{-1}$ ), benzo[g,h,i]perylene (BePe; $9.9 \mathrm{mg} \mathrm{L}^{-1}$ ), and indeno[1,2,3-c,d]pyrene (InPy; $9.8 \mathrm{mg} \mathrm{L}^{-1}$ ). Working standard solutions were prepared by diluting the standard solution in acetonitrile (HPLC quality, purity >
99.9\%, Chromasolv ${ }^{\circledR}$, Sigma-Aldrich). All solutions were stored at $4^{\circ} \mathrm{C}$ in dark to avoid solvent evaporation and/or degradation of PAHs by UV light. Uracil (purity: 99\%, Sigma-Aldrich), a nonretained compound in reversed phase, was dissolved in water (AnalaR Normapur, VWR, Fontenay-Sous-Bois, France) and used to determine void time $\left(t_{0}\right)$.

2.2. Equipment. The analyses were performed in an air conditioned room using a UFLC system (Prominence, Shimadzu, Tokyo, Japan), which consisted of the CBM-20A controller, the DGU-20A5R degassing unit, the LC-20AD pump, the SIL-20AC thermostated autosampler, and the CTO-20AC column oven. The two last pieces of equipment are able to regulate the temperature in a large range going from $4^{\circ} \mathrm{C}$ to $40^{\circ} \mathrm{C}$ and $10^{\circ} \mathrm{C}$ below room temperature to $85^{\circ} \mathrm{C}$, respectively. Finally, the SPD-M20A diode array detector and the LabSolutions software (Shimadzu) were used to control the system and acquire and process the data.

The separation of PAHs was performed by means of the $250 \mathrm{~mm} \times 4.6 \mathrm{~mm}$ Kinetex- $\mathrm{C}_{18}$ column packed with recent $5 \mu \mathrm{m}$ core-shell particles (Phenomenex, Le Pecq, France) and two other $250 \mathrm{~mm} \times 4.6 \mathrm{~mm}$ columns packed with $5 \mu \mathrm{m}$ fully porous particles, Supelcosil LC-PAH (Supelco, SigmaAldrich) and Spherisorb PAH (Alltech, Waters, Guyancourt, France).

2.3. UFLC-DAD Analysis. For the three columns studied, the mobile phase consisted of a mixture of acetonitrile and water with various composition and flow, depending on the analysis time (Table 1). Volume of solutions automatically injected was $20 \mu \mathrm{L}$ and the temperature of column oven ranged from $16^{\circ} \mathrm{C}$ to $30^{\circ} \mathrm{C}$. Wavelengths in relation with the maximum absorbance of each $\mathrm{PAH}$ were determined using the diode array detector (Table 2). These were used for the quantification of PAHs considering their relative peak areas. Each PAH identified its own retention time $\left(t_{R}\right)$ which was measured at peak apexes. The corrected retention times $\left(t_{R}^{\prime}\right)$ of PAHs were expressed as the difference between their respective retention time and the elution time of the nonretained uracil $\left(t_{0}\right)$. Limits of detection (LOD) and quantification (LOQ) were determined with a signal to noise ratio of 3 and 10 , respectively $[13,14]$.

2.4. Column Parameters. Peak widths $(\omega)$, half-height widths $(\delta)$, and half-widths at half-height $(\gamma)$ were employed in order to compare the properties of each peak obtained with those of a Gaussian one defined by the theoretical peak widths (see (1)) and half-widths at half-height (see (2)). In addition, the resolution (Rs) between two successive eluted PAHs was calculated following (3). Consider the following:

$$
\begin{aligned}
& \omega_{1}=1.7 \delta \\
& \gamma_{1}=\frac{\delta}{2} \\
& \mathrm{Rs}=\frac{2\left(t_{R(B)}-t_{R(A)}\right)}{\omega_{B}+\omega_{A}} .
\end{aligned}
$$


TABLE 1: Gradient used for the UFLC separation of the 16 PAHs.

\begin{tabular}{lcc}
\hline Time $(\mathrm{min})$ & $\mathrm{CH}_{3} \mathrm{CN}^{\mathrm{a}}(\%)$ & Flow $\left(\mathrm{mL} \mathrm{min}^{-1}\right)$ \\
\hline 0 & 70 & 0.8 \\
6.99 & 80 & 0.8 \\
$7.0-9.99$ & 80 & 0.7 \\
$11.0-13.2$ & & 1.0 \\
$13.25-16.0$ & & 0.7 \\
17.0 & 100 & \\
18.0 & 100 & 1.0 \\
22.0 & 100 & 1.0 \\
22.5 & 70 & 0.8 \\
\hline
\end{tabular}

${ }^{\mathrm{a}}$ Water was the other component of mobile phase.

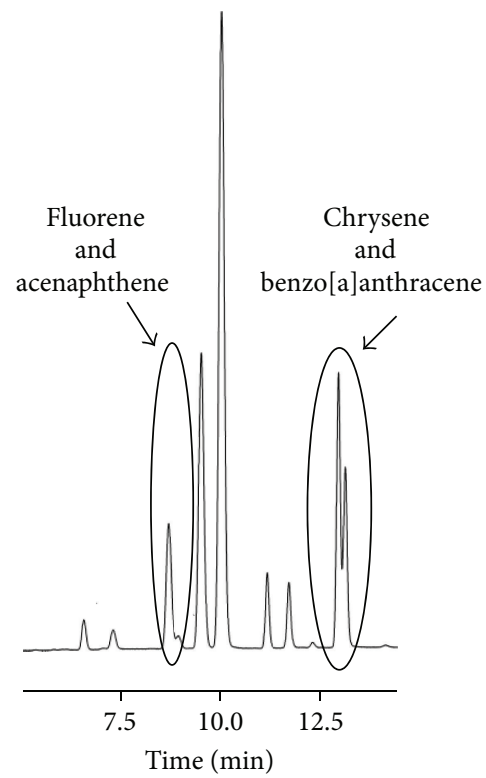

Figure 1: Example of coeluting peaks between fluorene/acenaphthene and chrysene/benzo[a]anthracene in the analysis of PAH.

\section{Results and Discussion}

3.1. Influence of the Temperature on the Separation of PAHs. Temperature was tested in order to study its effect on the separation of PAHs and on the peak resolution. Among the possible coeluting problems of the PAHs which have similar structures, two pairs of PAHs, Flu-Ace and Chr-BaA, were considered in the present study (Figure 1). The great interest in the diode array detector is the choice of the wavelengths used to integrate each of PAHs. In the case of the two pairs of PAHs studied, the wavelengths used to improve the sensibility of the analytical technic (Table 2) failed to completely remove one of the two PAH in order to integrate the second.

For each of the three columns studied, analyses were conducted after cooling or heating the autosampler and the column in an integrated column oven. Parts of the chromatogram obtained at $16,20,25$, and $30^{\circ} \mathrm{C}$ for fluorene and acenaphthene were summarized in Figures 2, 3, and 4. The results highlighted the fact that the temperature affects the retention time of the two PAHs studied when the columns packed with fully porous particles were used (Figures 2 and 3 ) and were in accordance with previous studies conducted with other pollutants [31-35].

The effectiveness of the separation of acenaphthene and fluorene depended on the temperature and the column. As shown in Figure 2, these two compounds were eluted at the same time and only one peak was obtained at 25 and $30^{\circ} \mathrm{C}$ and at $227 \mathrm{~nm}$. This result was quite different at $261 \mathrm{~nm}$. For both PAHs, the separation and the resolution were improved at 16 and $20^{\circ} \mathrm{C}$. In these conditions, the peaks were not very symmetric, this factor being one of problems in relation with the repeatability of measurements. As was the case for the Supelcosil LC-PAH column (Figure 2), acenaphthene was eluted before fluorene using the Spherisorb column (Figure 3). With this column, separation of acenaphthene and fluorene was not obtained whatever the experimental conditions studied (Figure 3). In contrast, these compounds were almost separated using the Kinetex column (Figure 4). These results were somewhat at odds with the previous ones due to the fact that (i) the elution order was not the same (fluorene and acenaphthene instead of acenaphthene and fluorene), (ii) the retention time was less impacted by the experimental temperature of the column (difference of time retention was 1 minute between the experiments at 16 and $30^{\circ} \mathrm{C}$ instead of 1.2-1.5 minute in the other two experiments), (iii) the retention time of each compound was the lowest, and (iv) peaks appeared as being the most symmetric, especially at $16^{\circ} \mathrm{C}$.

As shown in Figures 5 and 6, great effects of the temperature on the retention time and on the separation of benzo[a]anthracene and chrysene occurred by using the column packed with fully porous particles. The difference in time separation of these two compounds ranged from $0.739 \mathrm{~s}$ at $30^{\circ} \mathrm{C}$ to $1.31 \mathrm{~s}$ at $16^{\circ} \mathrm{C}$ and from $0.99 \mathrm{~s}$ at $30^{\circ} \mathrm{C}$ to $1.75 \mathrm{~s}$ at $16^{\circ} \mathrm{C}$ using the Supelcosil LC-PAH and the Spherisorb columns, respectively. In contrast, differences in time separation of these two PAHs were slightly different (from 0.165 to 0.273 minute) between both temperature conditions using the Kinetex column (Figure 7). The whole of these results highlighted the reduced retention of PAHs with core-shell particles of the Kinetex column resulting from the lower surface area of these particles compared to the fully porous particles of the two other columns used in this study. Furthermore, the structure of the particles, more homogeneous in the columns packed with core-shell particles than those with fully porous particles, allows the molecules to borrow shorter paths through this specific column than those in traditional columns $[25,36]$. Compared to the fully porous particles, Pereira (2012) showed a clear improvement in separation power using core-shell particle columns allowing faster separations at the same efficiency and higher separation resolution at the same analysis time [37].

Due to the fact that at $16^{\circ} \mathrm{C}$ the analysis of the 16 PAHs highlighted by the US Environmental Protection Agency (EPA) as priority pollutants was conducted in 35 and 47 minutes with the Supelcosil and the Spherisorb columns, respectively, the column packed with the $5 \mu \mathrm{m}$ core-shell particles was chosen to analyze them. The best temperature condition to separate these compounds was $16^{\circ} \mathrm{C}$. Surprisingly, 
TABLE 2: Specific wavelengths of the 16 PAHs studied.

\begin{tabular}{|c|c|c|c|c|c|c|c|c|c|c|c|c|c|c|c|c|}
\hline PAH & Naph & Acy & Flu & Ace & Phe & Anth & Fluo & Pyr & Chr & $\mathrm{BaA}$ & $\mathrm{BbF}$ & $\mathrm{BkF}$ & $\mathrm{BaP}$ & DiAn & InPy & $\mathrm{BePe}$ \\
\hline$\lambda(\mathrm{nm})$ & 220 & 228 & 260 & 225 & 250 & 251 & 235 & 240 & 266 & 286 & 255 & 306 & 295 & 295 & 249 & 299 \\
\hline
\end{tabular}
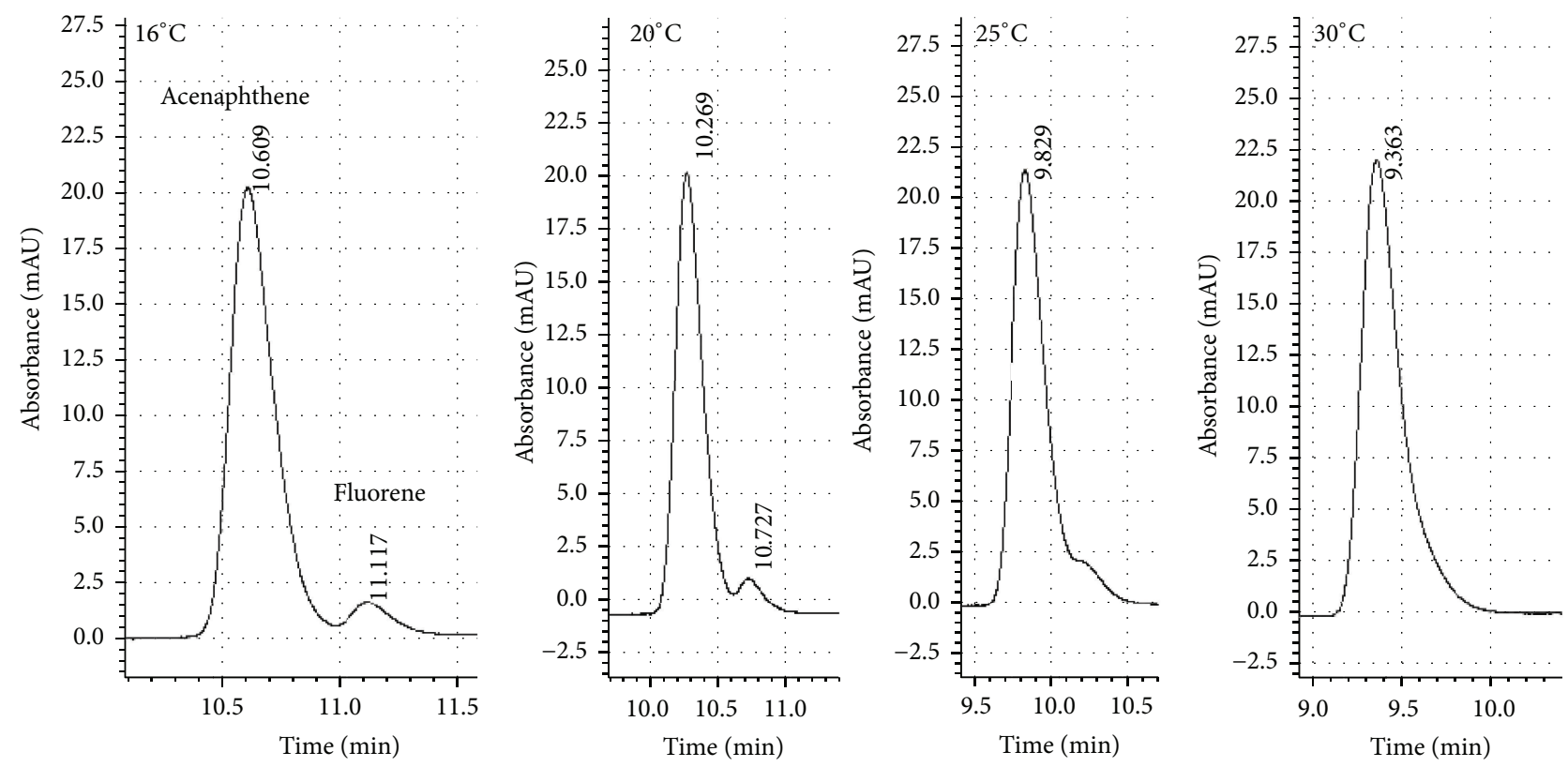

(a1)
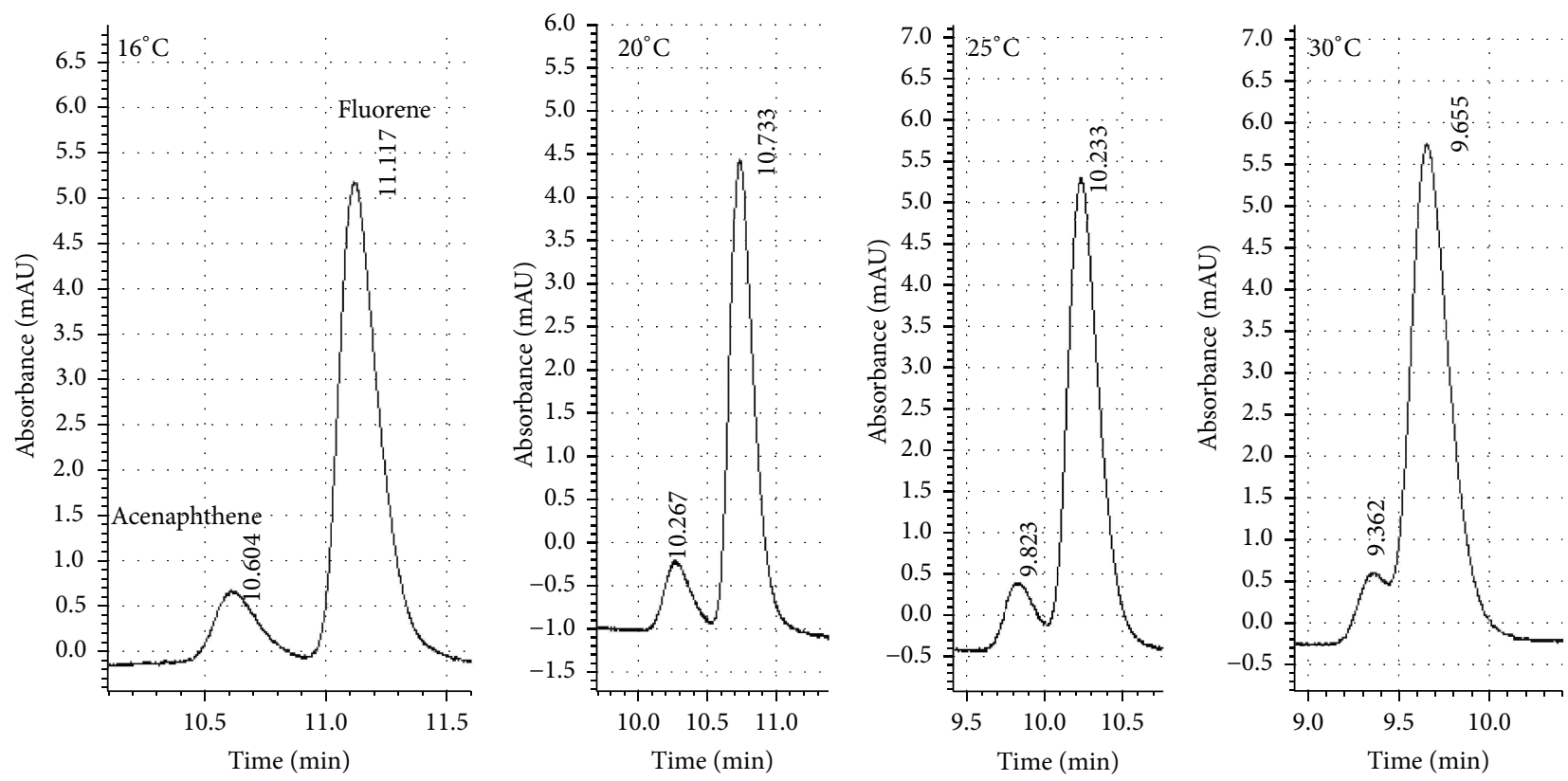

(b1)

FiguRE 2: Effect of the temperature on the separation of fluorene and acenaphthene using the Supelcosil LC-PAH column; (al) at $227 \mathrm{~nm}$; (b1) at $261 \mathrm{~nm}$. 

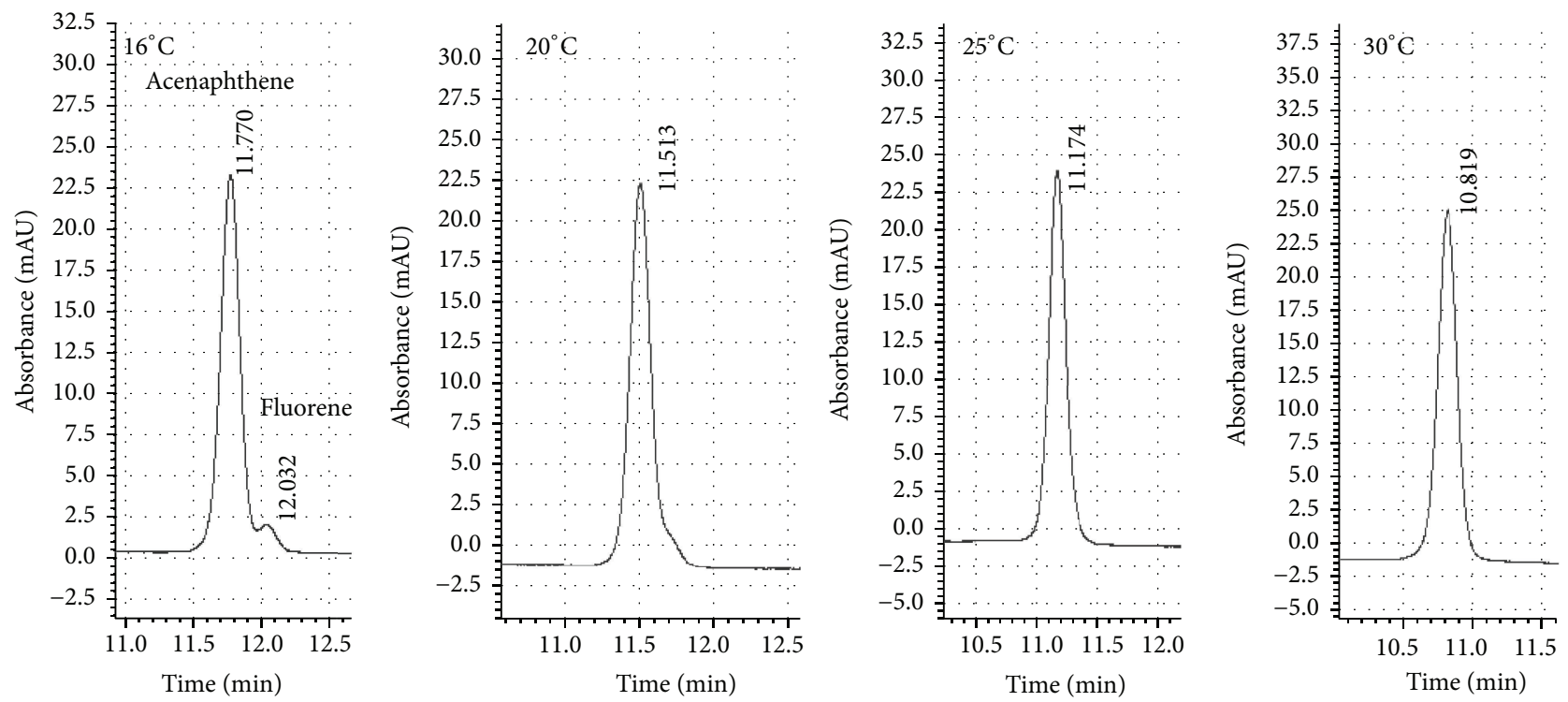

(a1)
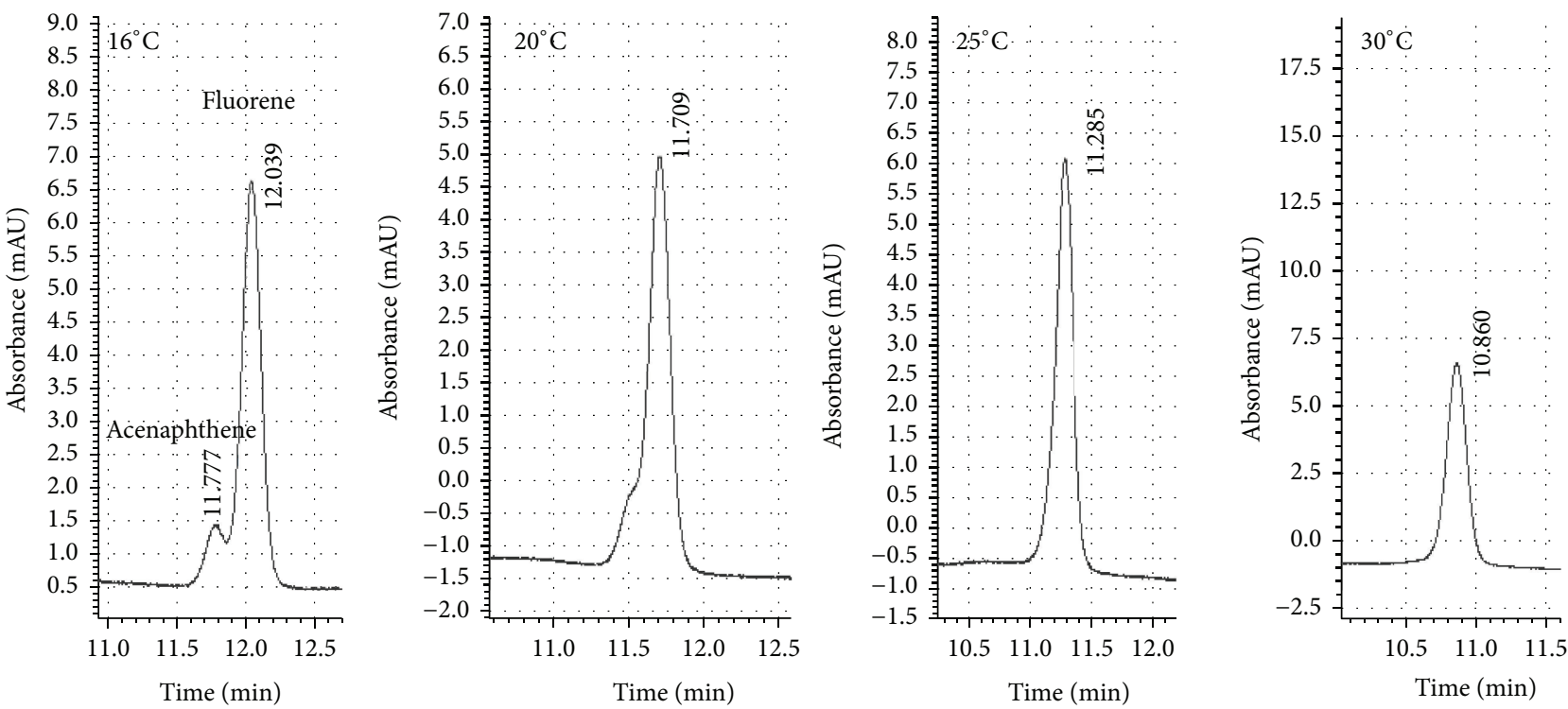

(b1)

FIGURE 3: Effect of the temperature on the separation of fluorene and acenaphthene using the Spherisorb column; (al) at $227 \mathrm{~nm}$; (bl) at $261 \mathrm{~nm}$.

the analysis time necessary to elute the 16 PAHs in this condition was nearly equal to that obtained at $30^{\circ} \mathrm{C}$ (Figure 8 ). With regard to the chromatogram obtained using this column at the four temperatures studied, it was highlighted that an increase of $5^{\circ} \mathrm{C}$ induced a decrease of 0.5 to 1 minute in the total analysis time. On the other hand, the separation of the 16 PAHs was operated at very low pressure (670-950 psi $=46-$ 65 bars). To finish, the resolution was similar at $16^{\circ} \mathrm{C}$ to the one obtained at $30^{\circ} \mathrm{C}$. Resolution values at $16^{\circ} \mathrm{C} / 30^{\circ} \mathrm{C}$ were 1.4/1.0, 1.0/0.9, 1.4/1.2, and 1.5/1.3 for Flu-Ace, Chr-BaA, BbF$\mathrm{BkF}$, and InPy-BePe, respectively.

3.2. Characteristics of the Chromatogram Obtained at $16^{\circ} \mathrm{C}$ Using the Kinetex Column. Retention times $\left(t_{R}^{\prime}\right)$, peak widths $(\omega)$, half-height peak widths $(\delta)$, and half-widths at halfheight $(\gamma)$ were measured for each peak on chromatogram obtained at $16^{\circ} \mathrm{C}$ using the column packed with the $5 \mu \mathrm{m}$ core-shell particles (Table 3 ). The experimental data $\omega, \delta$, and $\gamma$ were compared with the properties of Gaussian peak (theoretical value $\omega_{1}$ and $\gamma_{1}$ ). Regarding the theoretical and experimental values of peak widths, half-height peak widths, and half-widths at half-height for each PAH studied, the results clearly highlighted the fact that peaks obtained with the Kinetex column were symmetrical and may be considered as Gaussian peaks [30]. In spite of the advantages of this column, it has been shown that the impermeability of particle cores induced a reduction of interparticle mass transfer and an improvement of the efficiency $[26,30,38,39]$. 

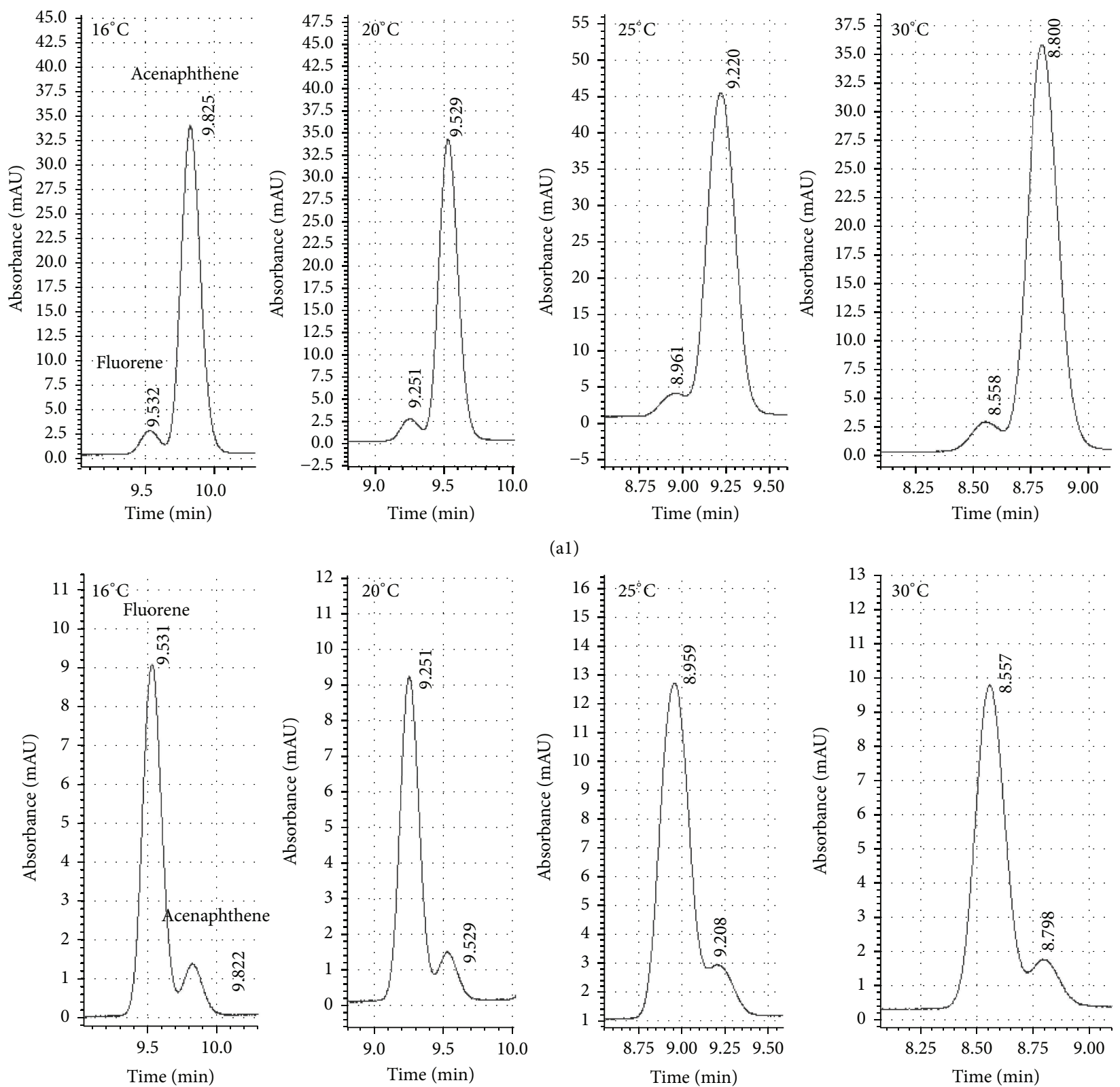

(a1)
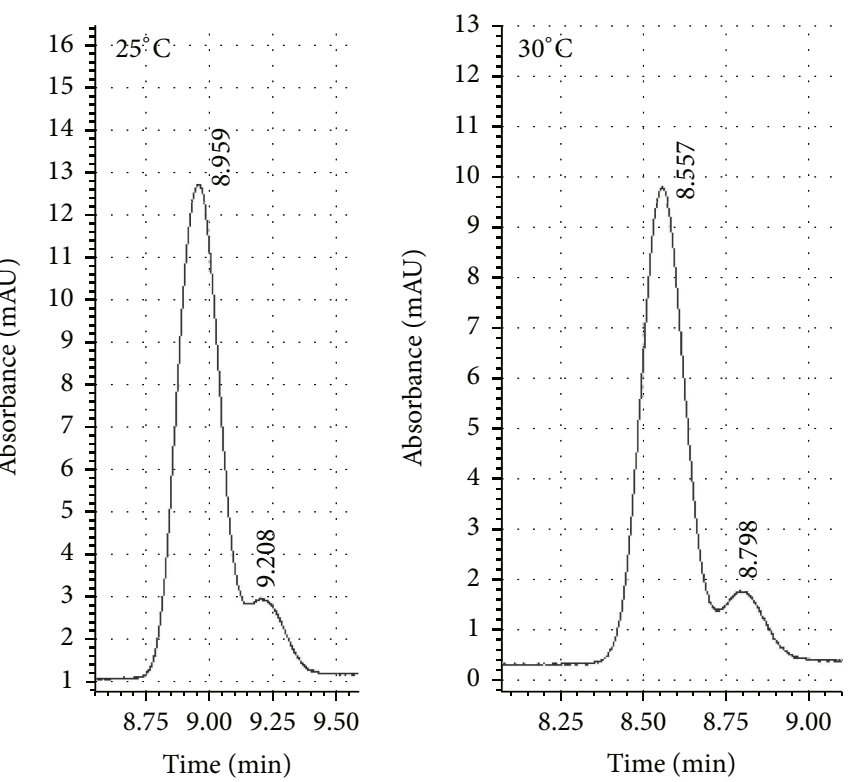

(b1)

FIGURE 4: Effect of the temperature on the separation of fluorene and acenaphthene using the Kinetex column; (al) at $227 \mathrm{~nm}$; (b1) at $261 \mathrm{~nm}$.

The resolution values were generally higher than 1.4 for the Kinetex column (Table 3). This result revealed a good separation of the PAHs. Nevertheless, an exception occurred for the pair BaA and $\mathrm{Chr}$, for which Rs was 1.0. This result has been considered as acceptable given the shortest possible analysis time to achieve the separation of the 16 PAHs studied [30] and the figure of merits described below.

3.3. Figures of Merit of the Analytical Method Using the Kinetex Columns at $16^{\circ} \mathrm{C}$. Linearity was studied using the 21 mixtures prepared from the standard solution (EPA-610). Their concentrations ranged from 1.25 to $1000 \mu \mathrm{g} \mathrm{L}^{-1}(1.25$, $2.5,5,7.5,10,12.5,25,37.5,50,62.5,75,87.5,100,125,250$,
$375,500,625,750,875$, and $\left.1000 \mu \mathrm{g} \mathrm{L}{ }^{-1}\right)$. The correlation coefficients were very good for the 16 PAHs studied. Limits of detection (LOD) and quantification (LOQ) were determined taking into account the $\mathrm{S} / \mathrm{N}$ ratio and were in the ranges 0.88 $9.16 \mu \mathrm{g} \mathrm{L}^{-1}$ and 2.95-30.53 $\mu \mathrm{g} \mathrm{L}^{-1}$, respectively, depending on PAHs (Table 4). Limit of detection found in this study was from 1.1 to 10.3 times lower than those obtained by Titato and Lanças [11] and 4.9 to 282 times lower than those calculated by Sun et al. [14].

The repeatability of the analytical method was investigated by injecting consecutively ten replicates of acetonitrile samples spiked with the $16 \mathrm{PAHs}$ at 10 and $50 \mu \mathrm{g} \mathrm{L}^{-1}$. The relative standard deviation (RSD) was calculated for each of 

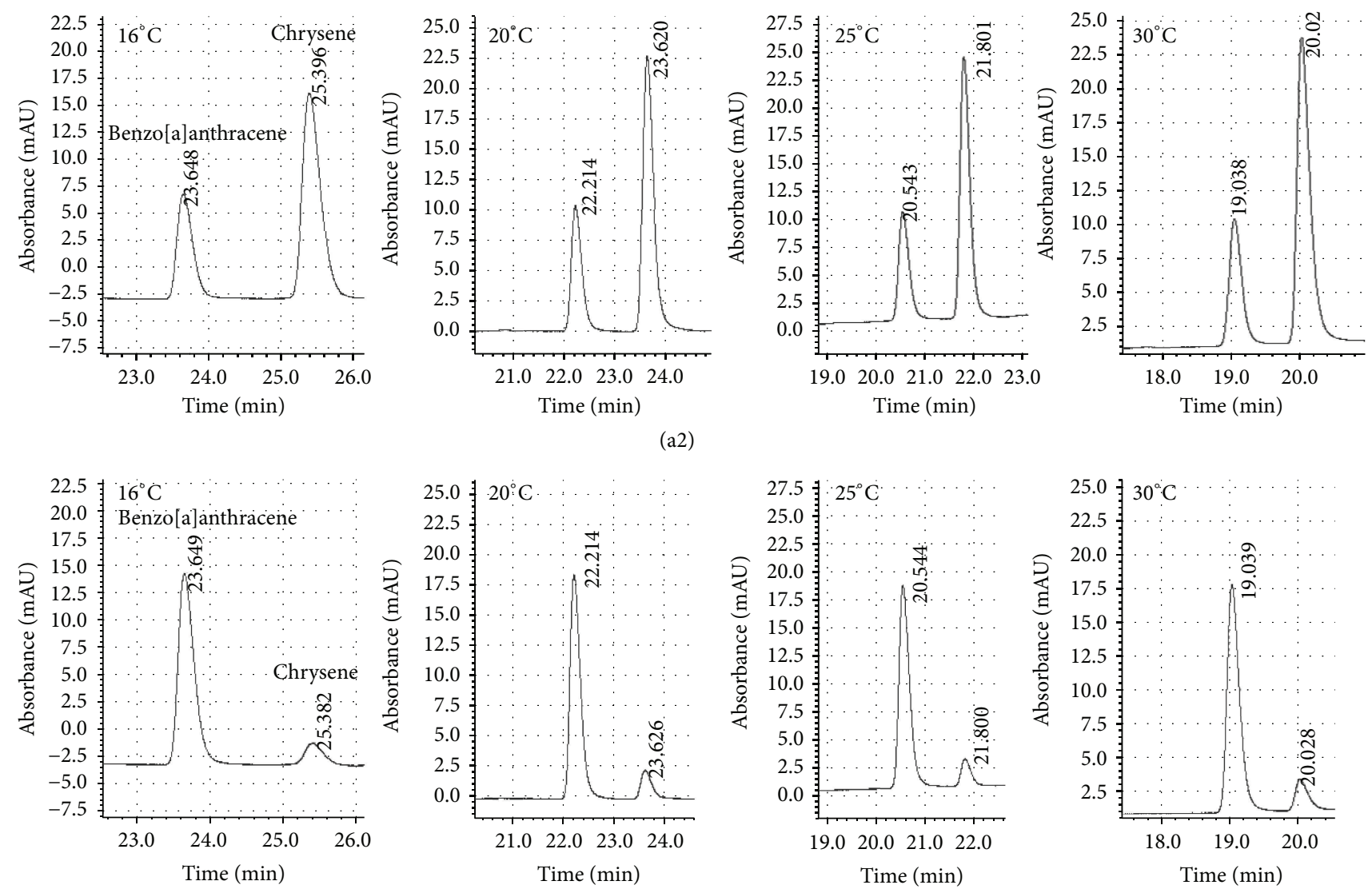

(b2)

FIGURE 5: Effect of the temperature on the separation of chrysene and Benzo[a]anthracene using the Supelcosil LC-PAH column; (a2) at $266 \mathrm{~nm}$; (b2) at $286 \mathrm{~nm}$.

TABLE 3: Peak characteristics of the 16 PAHs obtained with the Kinetex columns at $16^{\circ} \mathrm{C}$.

\begin{tabular}{|c|c|c|c|c|c|c|c|}
\hline \multirow{3}{*}{ PAH } & \multicolumn{7}{|c|}{ Kinetex } \\
\hline & \multicolumn{4}{|c|}{ Experimental data } & \multicolumn{3}{|c|}{ Calculated data } \\
\hline & $t_{R}^{\prime \mathrm{a}}$ & $\omega$ & $\delta$ & $\gamma$ & $\omega_{1}$ & $\gamma_{1}$ & Rs \\
\hline Naph & 4.413 & 0.171 & 0.100 & 0.048 & 0.170 & 0.050 & \\
\hline Acy & 5.373 & 0.187 & 0.109 & 0.053 & 0.185 & 0.055 & 5.4 \\
\hline Flu & 6.911 & 0.200 & 0.118 & 0.057 & 0.201 & 0.059 & 7.9 \\
\hline Ace & 7.204 & 0.207 & 0.121 & 0.059 & 0.206 & 0.061 & 1.4 \\
\hline Phe & 7.878 & 0.176 & 0.103 & 0.051 & 0.175 & 0.052 & 3.5 \\
\hline Anth & 8.338 & 0.158 & 0.093 & 0.045 & 0.158 & 0.047 & 2.7 \\
\hline Fluo & 9.494 & 0.167 & 0.098 & 0.048 & 0.167 & 0.049 & 7.1 \\
\hline Pyr & 10.193 & 0.177 & 0.103 & 0.050 & 0.175 & 0.052 & 4.1 \\
\hline Chr & 12.232 & 0.289 & 0.170 & 0.083 & 0.289 & 0.085 & 8.7 \\
\hline $\mathrm{BaA}$ & 12.514 & 0.296 & 0.172 & 0.083 & 0.292 & 0.086 & 1.0 \\
\hline $\mathrm{BbF}$ & 15.467 & 0.203 & 0.119 & 0.058 & 0.202 & 0.060 & 11.8 \\
\hline $\mathrm{BkF}$ & 15.740 & 0.199 & 0.117 & 0.058 & 0.199 & 0.059 & 1.4 \\
\hline $\mathrm{BaP}$ & 16.374 & 0.198 & 0.118 & 0.058 & 0.201 & 0.059 & 3.2 \\
\hline DiAn & 17.292 & 0.178 & 0.104 & 0.051 & 0.177 & 0.052 & 4.9 \\
\hline InPy & 18.314 & 0.169 & 0.100 & 0.049 & 0.170 & 0.050 & 5.8 \\
\hline $\mathrm{BePe}$ & 18.573 & 0.169 & 0.101 & 0.049 & 0.172 & 0.051 & 1.5 \\
\hline
\end{tabular}

${ }^{\mathrm{a}} t_{R}^{\prime}(\mathrm{min})$ was calculated from value to $t_{0}=2.752$. 

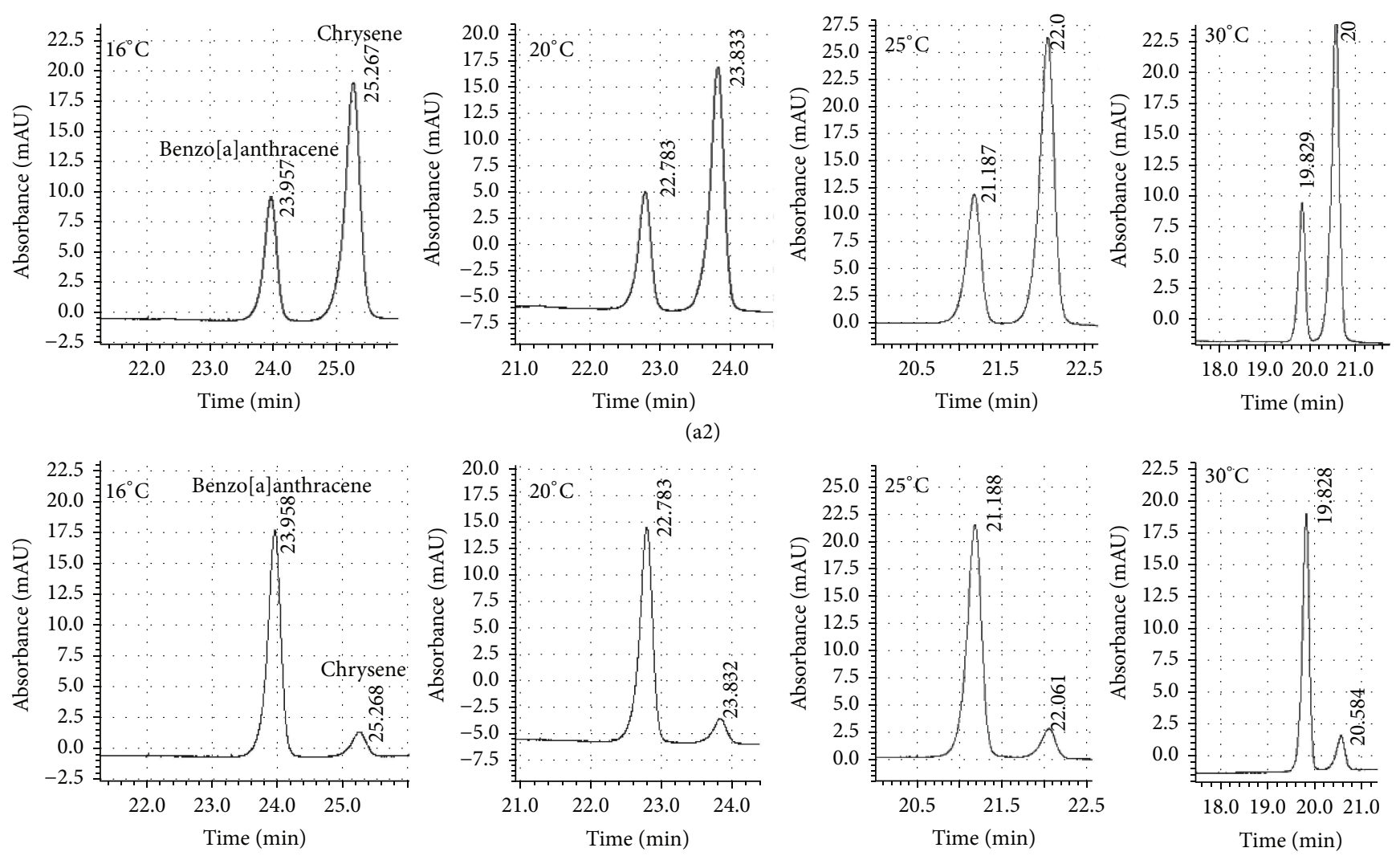

(b2)

FIGURE 6: Influence of column temperature on the separation of chrysene and benzo[a]anthracene using the Spherisorb column; (a2) at $266 \mathrm{~nm}$; (b2) at $286 \mathrm{~nm}$.

TABLE 4: Linearity, limits of detection (LOD), and quantification (LOQ) of the analytical method with the Kinetex column at $16^{\circ} \mathrm{C}$.

\begin{tabular}{lccc}
\hline PAH & \multicolumn{3}{c}{ Linearity $1.25^{\mathrm{a}}-1000 \mu \mathrm{g} \mathrm{L}^{-1}$} \\
& $R$ & LOD $\left(\mu \mathrm{g} \mathrm{L}^{-1}\right)$ & LOQ $\left(\mu \mathrm{g} \mathrm{L}^{-1}\right)$ \\
\hline Naph & 0.9999 & 0.88 & 2.95 \\
Acy & 1.0000 & 2.80 & 9.32 \\
Flu & 0.9999 & 9.16 & 30.53 \\
Ace & 1.0000 & 2.04 & 6.80 \\
Phe & 0.9999 & 2.99 & 9.96 \\
Anth & 1.0000 & 1.32 & 4.39 \\
Fluo & 1.0000 & 4.08 & 13.59 \\
Pyr & 1.0000 & 3.09 & 10.29 \\
Chr & 0.9997 & 2.81 & 9.37 \\
BaA & 0.9998 & 4.96 & 16.53 \\
BbF & 1.0000 & 7.43 & 24.76 \\
BkF & 1.0000 & 6.02 & 20.07 \\
BaP & 0.9999 & 7.82 & 26.08 \\
DiAn & 1.0000 & 2.89 & 9.63 \\
InPy & 1.0000 & 4.53 & 15.10 \\
BePe & 0.9999 & 7.36 & 24.54 \\
\hline
\end{tabular}

${ }^{\text {a }}$ Prepared solutions with concentration below LOD were not considered.

the PAHs from their respective peak areas and retention times (Table 5). Regarding the results, very low RSD values related to the area variation (below 3\%) and recoveries ranged from 96.6 to $109.3 \%$. Depending on PAHs, their concentrations in the acetonitrile samples prepared at around 10 and $50 \mu \mathrm{g} \mathrm{L}^{-1}$ were in the range $9.63 \pm 0.06-11.08 \pm 0.26$ and $49.72 \pm 0.42-$ $53.40 \pm 0.66 \mu \mathrm{g} \mathrm{L}^{-1}$, respectively. To complete the study, a similar procedure was applied with tap water samples spiked with PAHs at around $10 \mu \mathrm{g} \mathrm{L}^{-1}$. The PAHs were selected taking into account their solubility in water. Therefore, the mixture of PAHs was composed by naphthalene, acenaphthylene, fluorine, acenaphthene, phenanthrene, anthracene, fluoranthene, pyrene, benzo[a]anthracene, benzo[b]fluoranthene, and indeno[1,2,3-c,d]pyrene. The results were summarized in Table 5 and were expressed as mean concentrations $( \pm$ standard deviation, $n=10$ ). The recoveries ranged from 94 to $102 \%$ and the precision values, expressed as the RSD, were between 1 and $3.5 \%$. The whole of these results suggests the excellent repeatability of the analytical procedure and is in accordance with recent studies in which the authors highlighted that it was possible to achieve UHPLC-equivalent performance from a conventional HPLC system coupled with columns packed with core-shell particles [40-42].

\section{Conclusion}

The use of recent $5 \mu \mathrm{m}$ core-shell particles of the Kinetex column allowed a fast separation of 16 PAHs at $16^{\circ} \mathrm{C}$ and 

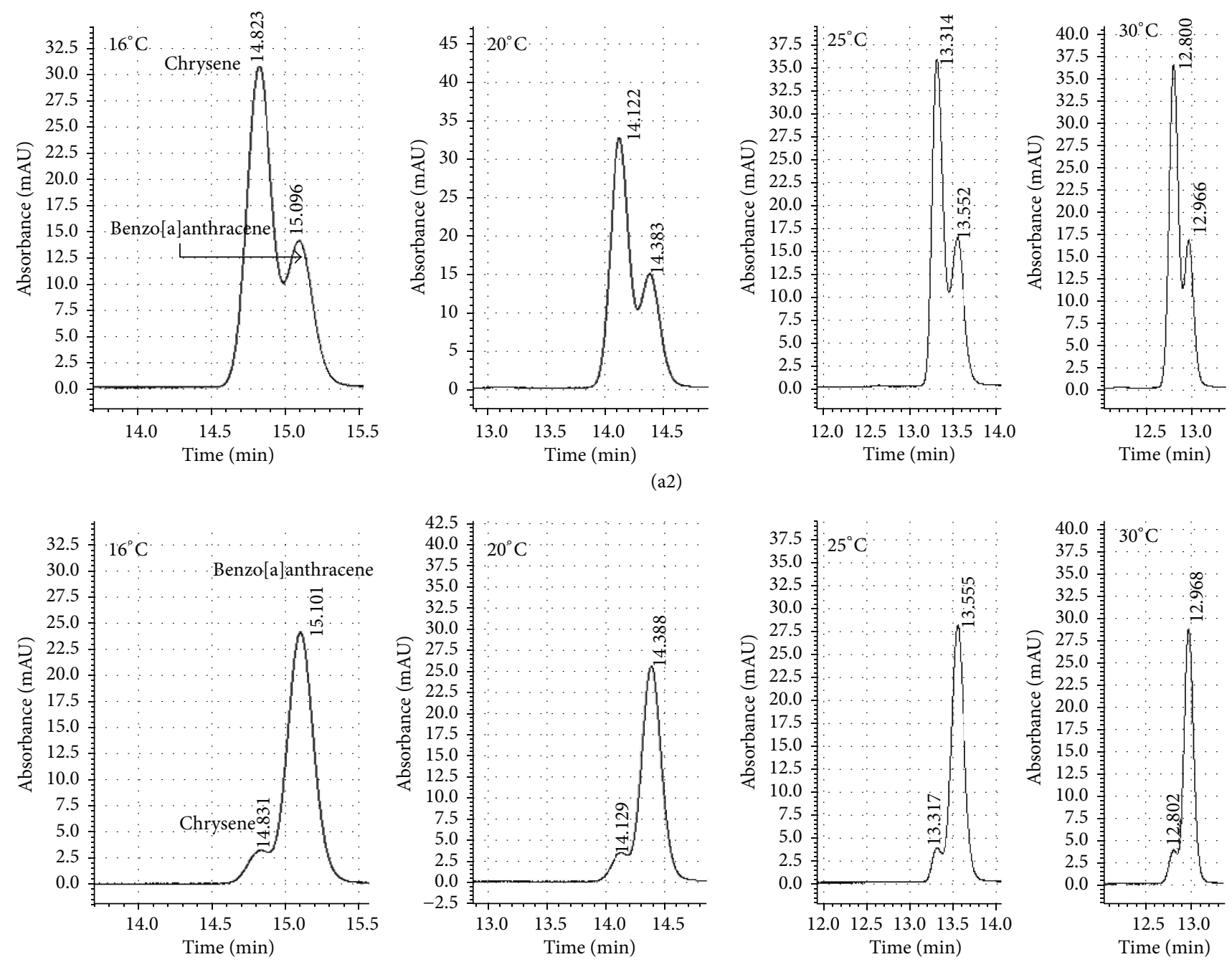

FiguRE 7: Influence of column temperature on the separation of chrysene and benzo[a]anthracene using the Kinetex LC-PAH column; (a2) at $266 \mathrm{~nm}$; (b2) at $286 \mathrm{~nm}$.
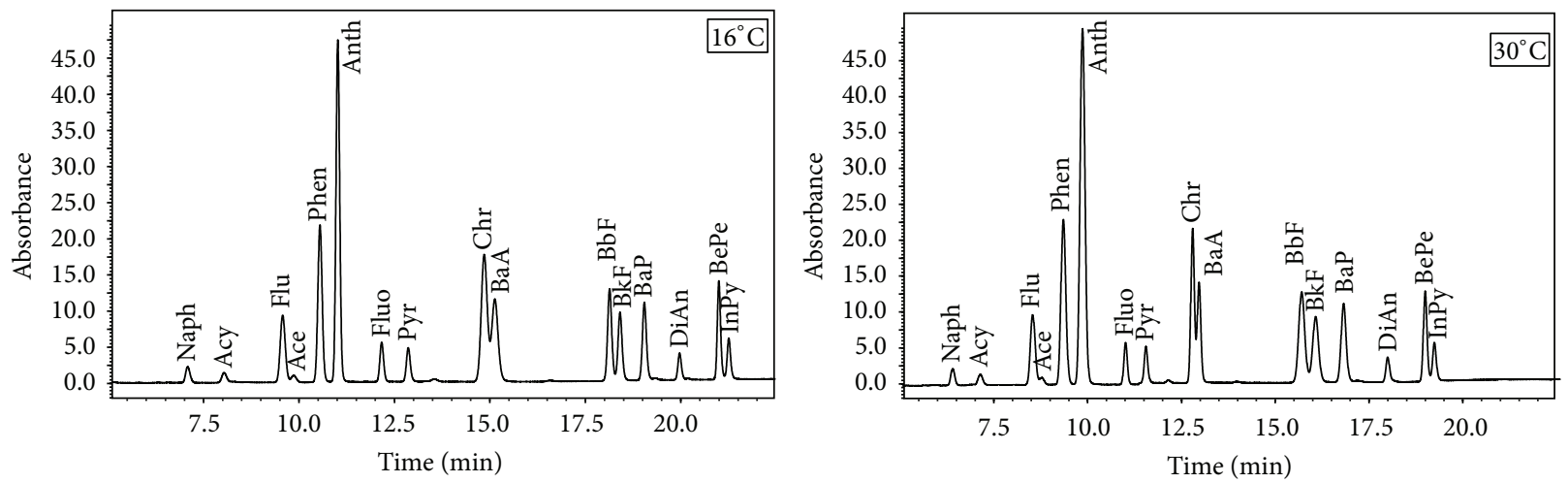

FIGURE 8: Chromatograms of $16 \mathrm{PAHs}$ at $500 \mu \mathrm{g} \mathrm{L} \mathrm{L}^{-1}$ obtained with Kinetex at $254 \mathrm{~nm}$ : temperature-dependent solute retention time variations. 
TABLE 5: Repeatability of the analytical method using acetonitrile samples spiked with PAH at around 50 and $10 \mu \mathrm{g} \mathrm{L}^{-1}$ and tap water samples spiked at around $10 \mu \mathrm{g} \mathrm{L}^{-1}$.

\begin{tabular}{|c|c|c|c|c|c|c|}
\hline \multirow{3}{*}{ PAH } & \multicolumn{4}{|c|}{ Spiked acetonitrile samples } & \multirow{2}{*}{\multicolumn{2}{|c|}{$\begin{array}{l}\text { Spiked tap water samples } \\
\text { At around } 10 \mu \mathrm{g} \mathrm{L}^{-1}(n=10)^{\mathrm{c}}\end{array}$}} \\
\hline & \multicolumn{2}{|c|}{ At around $50 \mu \mathrm{g} \mathrm{L}^{-1}(n=10)^{\mathrm{a}}$} & \multicolumn{2}{|c|}{ At around $10 \mu \mathrm{g} \mathrm{L}^{-1}(n=10)^{\mathrm{b}}$} & & \\
\hline & Area (RSD\%) & Concentration $\left(\mu \mathrm{g} \mathrm{L}^{-1}\right)^{\mathrm{d}}$ & Area (RSD\%) & Concentration $\left(\mu \mathrm{g} \mathrm{L}^{-1}\right)^{\mathrm{d}}$ & Area (RSD\%) & Concentration $\left(\mu \mathrm{g} \mathrm{L}^{-1}\right)^{\mathrm{d}}$ \\
\hline Naph & 1.75 & $50.25 \pm 0.88$ & 1.87 & $10.75 \pm 0.20$ & 1.75 & $9.80 \pm 0.17$ \\
\hline Acy & 0.19 & $51.04 \pm 0.10$ & 1.03 & $9.81 \pm 0.10$ & 0.19 & $10.19 \pm 0.10$ \\
\hline Flu & 0.63 & $51.99 \pm 0.33$ & 2.31 & $11.08 \pm 0.26$ & 0.63 & $9.43 \pm 0.20$ \\
\hline Ace & 0.19 & $51.03 \pm 0.10$ & 1.11 & $10.22 \pm 0.11$ & 0.19 & $9.68 \pm 0.14$ \\
\hline Phe & 1.08 & $51.78 \pm 0.56$ & 1.42 & $10.45 \pm 0.15$ & 1.08 & $9.57 \pm 0.15$ \\
\hline Anth & 0.54 & $51.65 \pm 0.28$ & 2.44 & $10.15 \pm 0.25$ & 0.54 & $9.95 \pm 0.14$ \\
\hline Fluo & 0.62 & $51.06 \pm 0.32$ & 1.72 & $10.04 \pm 0.17$ & 0.62 & $9.96 \pm 0.17$ \\
\hline Pyr & 0.29 & $51.25 \pm 0.15$ & 1.71 & $10.19 \pm 0.17$ & 0.29 & $9.71 \pm 0.13$ \\
\hline Chr & 0.56 & $51.04 \pm 0.29$ & 2.11 & $10.29 \pm 0.22$ & nd & nd \\
\hline $\mathrm{BaA}$ & 0.95 & $51.15 \pm 0.49$ & 2.17 & $10.13 \pm 0.22$ & 0.95 & $9.86 \pm 0.31$ \\
\hline $\mathrm{BbF}$ & 1.38 & $50.31 \pm 0.70$ & 1.88 & $10.13 \pm 0.19$ & 1.38 & $9.79 \pm 0.29$ \\
\hline $\mathrm{BkF}$ & 0.84 & $49.72 \pm 0.42$ & 1.05 & $10.82 \pm 0.11$ & nd & nd \\
\hline $\mathrm{BaP}$ & 1.48 & $52.11 \pm 0.77$ & 0.62 & $9.63 \pm 0.06$ & nd & nd \\
\hline DiAn & 0.59 & $51.46 \pm 0.31$ & 2.53 & $10.37 \pm 0.26$ & nd & nd \\
\hline InPy & 0.57 & $50.99 \pm 0.29$ & 3.05 & $10.31 \pm 0.31$ & 0.57 & $9.81 \pm 0.26$ \\
\hline $\mathrm{BePe}$ & 1.23 & $53.40 \pm 0.66$ & 1.48 & $11.03 \pm 0.16$ & nd & nd \\
\hline
\end{tabular}

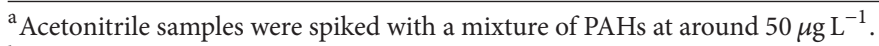

${ }^{\mathrm{b}}$ Acetonitrile samples were spiked with a mixture of PAHs at around $10 \mu \mathrm{g} \mathrm{L}^{-1}$.

${ }^{\mathrm{c}}$ Tap water was spiked with a mixture of PAHs (Naph, Acy, Flu, Ace, Phe, Anth, Fluo, Pyr, BaA, BbF, and InPy) at around $10 \mu g \mathrm{~L}^{-1}$. These PAHs were selected from their solubility values in water.

${ }^{\mathrm{d}}$ Concentrations were expressed as mean $\pm \mathrm{SD}$.

nd: not determined.

operating at very low pressure $(670-950$ psi $=46-65$ bars $)$. These conditions were perfectly adapted to avoid the solvent evaporation, to stabilize PAHs with the lowest molecular mass, and to increase the lifetime of columns. Although the efficiency of columns packed with core-shell particles has been already demonstrated in previous studies, this work showed that the 16 PAHs of the mixture EPA-610 Oekanal could be separated and analyzed using DAD detector without major changing in terms of retention time and peak resolution considering the temperature as variable. Consequently, the separation of PAHs using a column packed with coreshell particles may be performed without thermostatically controlled oven whereas it is essential for the separation of these pollutants using columns packed with fully porous particles.

In view of the detector used in the present study (DAD), low detection and quantification limits were obtained (from 0.88 to $9.16 \mu \mathrm{g} \mathrm{L}^{-1}$ ). To complete this study, analytical determinations of PAH concentrations in spiked acetonitrile samples at 10 and $50 \mu \mathrm{g} \mathrm{L}^{-1}$ and tap water at $10 \mu \mathrm{g} \mathrm{L}^{-1}$ were conducted. Results showed very good recoveries (94\%$109.3 \%)$ and high precision (1.1-3.5\%). The high sensitivity of the system composed by the Shimadzu UFLC in combination with the column packed with the recent $5 \mu \mathrm{m}$ KinetexC18 core-shell particles should allow for earlier detection of PAHs in contaminated samples (soil, sediment, and dust) and should be used to evaluate the effects of chemical amendments in the immobilization of these organic pollutants.

\section{Competing Interests}

The authors declare that they have no competing interests.

\section{References}

[1] R. Harkov, "Toxic air pollutants-assessing their importance," Science of the Total Environment, vol. 26, no. 1, pp. 67-85, 1982.

[2] M. Muntaz and J. George, Toxicological Profile for Polycyclic Aromatic Hydrocarbons, ATSDR, Atlanta, Ga, USA, 1995.

[3] A. Singh, K. Chandrasekharan Nair, R. Kamal et al., "Assessing hazardous risks of indoor airborne polycyclic aromatic hydrocarbons in the kitchen and its association with lung functions and urinary PAH metabolites in kitchen workers," Clinica Chimica Acta, vol. 452, pp. 204-213, 2016.

[4] P. Rajput, M. Sarin, and R. Rengarajan, "High-precision GClMS analysis of atmospheric polycyclic aromatic hydrocarbons (PAHs) and isomer ratios from biomass burning emissions," Journal of Environmental Protection, vol. 2, pp. 445-453, 2011.

[5] S. K. Pandey, K.-H. Kim, and R. J. C. Brown, "A review of techniques for the determination of polycyclic aromatic hydrocarbons in air," TrAC - Trends in Analytical Chemistry, vol. 30, no. 11, pp. 1716-1739, 2011.

[6] M. S. Nawaz, F. K. Ferdousi, M. A. Rahman, and A. M. Alam, "Reversed phase SPE and GC-MS study of polycyclic aromatic hydrocarbons in water samples from the river buriganga, bangladesh," International Scholarly Research Notices, vol. 2014, Article ID 234092, 9 pages, 2014. 
[7] A. Belles, Y. Mamindy-Pajany, and C. Alary, "Simulation of aromatic polycyclic hydrocarbons remobilization from a river sediment using experiments supported by passive sampling techniques," Environmental Science and Pollution Research, vol. 23, pp. 2426-2436, 2016.

[8] J. D. Berset, M. Ejem, R. Holzer, and P. Lischer, "Comparison of different drying, extraction and detection techniques for the determination of priority polycyclic aromatic hydrocarbons in background contaminated soil samples," Analytica Chimica Acta, vol. 383, no. 3, pp. 263-275, 1999.

[9] G.-W. Lien, C.-Y. Chen, and C.-F. Wu, "Analysis of polycyclic aromatic hydrocarbons by liquid chromatography/tandem mass spectrometry using atmospheric pressure chemical ionization or electrospray ionization with tropylium post-column derivatization," Rapid Communications in Mass Spectrometry, vol. 21, no. 22, pp. 3694-3700, 2007.

[10] S.-C. C. Lung and C.-H. Liu, "Fast analysis of 29 polycyclic aromatic hydrocarbons (PAHs) and nitro-PAHs with ultrahigh performance liquid chromatography-atmospheric pressure photoionization-tandem mass spectrometry," Scientific Reports, vol. 5, Article ID 12992, pp. 1-13, 2015.

[11] G. M. Titato and F. M. Lanças, "Optimization and validation of HPLC-UV-DAD and HPLC-APCI-MS methodologies for the determination of selected PAHs in water samples," Journal of Chromatographic Science, vol. 44, no. 1, pp. 35-40, 2006.

[12] L. D. Gratz, S. T. Bagley, D. G. Leddy, J. H. Johnson, C. Chiu, and P. Stommel, "Interlaboratory comparison of HPLCfluorescence detection and GC/MS: analysis of PAH compounds present in diesel exhaust," Journal of Hazardous Materials, vol. 74, no. 1-2, pp. 37-46, 2000.

[13] J. L. Santos, I. Aparicio, and E. Alonso, "A new method for the routine analysis of LAS and PAH in sewage sludge by simultaneous sonication-assisted extraction prior to liquid chromatographic determination," Analytica Chimica Acta, vol. 605, no. 1, pp. 102-109, 2007.

[14] F. Sun, D. Littlejohn, and M. D. Gibson, "Ultrasonication extraction and solid phase extraction clean-up for determination of US EPA 16 priority pollutant polycyclic aromatic hydrocarbons in soils by reversed-phase liquid chromatography with ultraviolet absorption detection," Analytica Chimica Acta, vol. 364, no. 1-3, pp. 1-11, 1998.

[15] L. C. Sander and S. A. Wise, "Synthesis and characterization of polymeric C18 stationary phases for liquid chromatography," Analytical Chemistry, vol. 56, no. 3, pp. 504-510, 1984.

[16] S. A. Wise and L. C. Sander, "Factors affecting the reversedphase liquid chromatographic separation of polycyclic aromatic hydrocarbon isomers," Journal of High Resolution Chromatography, vol. 8, pp. 248-255, 1985.

[17] L. C. Sander and S. A. Wise, "Determination of column selectivity toward polycyclic aromatic hydrocarbons," Journal of High Resolution Chromatography, vol. 11, no. 5, pp. 383-387, 1988.

[18] L. C. Sander and S. A. Wise, "Effect of phase length on column selectivity for the separation of polycyclic aromatic hydrocarbons by reversed-phase liquid chromatography," Analytical Chemistry, vol. 59, no. 18, pp. 2309-2313, 1987.

[19] L. C. Sander and S. A. Wise, "Subambient temperature modification of selectivity in reversed-phase liquid chromatography," Analytical Chemistry, vol. 61, no. 15, pp. 1749-1754, 1989.
[20] K. B. Sentell and J. G. Dorsey, "Retention mechanisms in reversed-phase liquid chromatography. Stationary-phase bonding density and partitioning," Analytical Chemistry, vol. 61, no. 9, pp. 930-934, 1989.

[21] E. Oláh, S. Fekete, J. Fekete, and K. Ganzler, "Comparative study of new shell-type, sub- $2 \mu \mathrm{m}$ fully porous and monolith stationary phases, focusing on mass-transfer resistance," Journal of Chromatography A, vol. 1217, no. 23, pp. 3642-3653, 2010.

[22] S. Fekete, K. Ganzler, and J. Fekete, "Efficiency of the new sub- $2 \mu \mathrm{m}$ core-shell (Kinetex ${ }^{\mathrm{TM}}$ ) column in practice, applied for small and large molecule separation," Journal of Pharmaceutical and Biomedical Analysis, vol. 54, no. 3, pp. 482-490, 2011.

[23] K. Miyabe, "Moment equations for chromatography using superficially porous spherical particles," Analytical Sciences, vol. 27, no. 10, pp. 1007-1017, 2011.

[24] J. J. DeStefano, T. J. Langlois, and J. J. Kirkland, "Characteristics of superficially-porous silica particles for fast HPLC: some performance comparisons with sub- $2 \mu \mathrm{m}$ particles," Journal of Chromatographic Science, vol. 46, no. 3, pp. 254-260, 2008.

[25] G. Guiochon and F. Gritti, "Shell particles, trials, tribulations and triumphs," Journal of Chromatography A, vol. 1218, no. 15, pp. 1915-1938, 2011.

[26] V. González-Ruiz, A. I. Olives, and M. A. Martín, “Core-shell particles lead the way to renewing high-performance liquid chromatography," TrAC-Trends in Analytical Chemistry, vol. 64, pp. 17-28, 2015.

[27] F. Gritti and G. Guiochon, "Mass transfer mechanism in liquid chromatography columns packed with shell particles: would there be an optimum shell structure?" Journal of Chromatography A, vol. 1217, no. 52, pp. 8167-8180, 2010.

[28] J. Urban, P. Jandera, Z. Kutčerová, M. A. van Straten, and H. A. Claessens, "A study of the effects of column porosity on gradient separations of proteins," Journal of Chromatography A, vol. 1167, no. 1, pp. 63-75, 2007.

[29] R. Kamour, A. Ammar, M. El-Attug, and T. Almog, "Development of fused-core silica HPLC columns and their recent pharmaceutical and biological applications: a review," International Journal of Pharmacy and Pharmaceutical Sciences, vol. 5, no. 3, pp. 926-930, 2013.

[30] F. Gritti and G. Guiochon, "Perspectives on the evolution of the column efficiency in liquid chromatography," Analytical Chemistry, vol. 85, no. 6, pp. 3017-3035, 2013.

[31] F. Lestremau, A. Cooper, R. Szucs, F. David, and P. Sandra, "High-efficiency liquid chromatography on conventional columns and instrumentation by using temperature as a variable: I. Experiments with $25 \mathrm{~cm} \times 4.6 \mathrm{~mm}$ I.D., $5 \mu \mathrm{m}$ ODS columns," Journal of Chromatography A, vol. 1109, no. 2, pp. 191196, 2006.

[32] P. Jandera, K. Krupczyńska, K. Vyňuchalová, and B. Buszewski, "Combined effects of mobile phase composition and temperature on the retention of homologous and polar test compounds on polydentate $\mathrm{C}_{8}$ column," Journal of Chromatography A, vol. 1217, no. 39, pp. 6052-6060, 2010.

[33] J. Soukup and P. Jandera, "The effect of temperature and mobile phase composition on separation mechanism of flavonoid compounds on hydrosilated silica-based columns," Journal of Chromatography A, vol. 1245, pp. 98-108, 2012.

[34] J. Soukup and P. Jandera, "Hydrosilated silica-based columns: the effects of mobile phase and temperature on dual hydrophilic-reversed-phase separation mechanism of phenolic acids," Journal of Chromatography A, vol. 1228, pp. 125-134, 2012. 
[35] J. Ruta, D. Guillarme, S. Rudaz, and J.-L. Veuthey, "Comparison of columns packed with porous sub- $2 \mu \mathrm{m}$ particles and superficially porous sub- $3 \mu \mathrm{m}$ particles for peptide analysis at ambient and high temperature," Journal of Separation Science, vol. 33, no. 16, pp. 2465-2477, 2010.

[36] F. Gritti and G. Guiochon, "Facts and legends on columns packed with sub-3- $\mu \mathrm{m}$ core-shell particles," LCGC North America, vol. 30, no. 7, pp. 586-595, 2012.

[37] L. Pereira, "An overview of core enhanced technology for fast, high efficiency HPLC," Chromatography Today, 2012.

[38] F. Gritti and G. Guiochon, "Non-invasive measurement of eddy diffusion in very efficient liquid chromatography columns packed with sub-3 $\mu \mathrm{m}$ shell particles," Chemical Engineering Science, vol. 65, no. 23, pp. 6327-6340, 2010.

[39] K. Broeckhoven, D. Cabooter, and G. Desmet, "Kinetic performance comparison of fully and superficially porous particles with sizes ranging between $2.7 \mu \mathrm{m}$ and $5 \mu \mathrm{m}$ : intrinsic evaluation and application to a pharmaceutical test compound," Journal of Pharmaceutical Analysis, vol. 3, no. 5, pp. 313-323, 2013.

[40] J. Layne and S. Lomas, "Maximising core-shell performance on conventional HPLC systems," Chromatography Today, 3 pages, 2012.

[41] G. Vinci, M. L. Antonelli, and R. Preti, "Rapid determination of polycyclic aromatic hydrocarbons in rainwater by liquid-liquid microextraction and LC with core-shell particles column and fluorescence detection," Journal of Separation Science, vol. 36, no. 3, pp. 461-468, 2013.

[42] J. Ye, X. Cao, Z. Cheng, Y. Qin, and Y. Lu, "Rapid determination of parabens in seafood sauces by high-performance liquid chromatography: a practical comparison of core-shell particles and sub-2 $\mu \mathrm{m}$ fully porous particles," Journal of Separation Science, vol. 38, no. 23, pp. 3992-3999, 2015. 

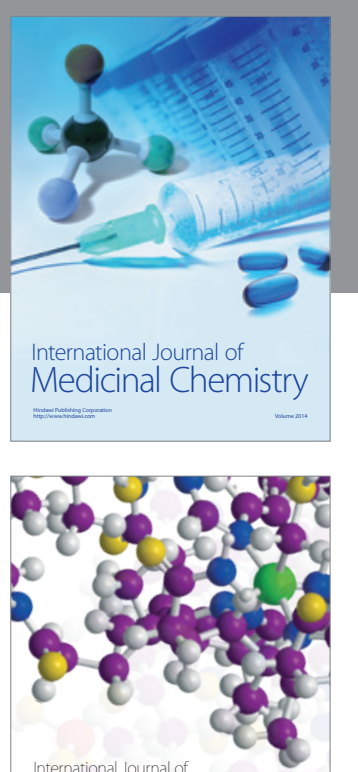

Carbohydrate Chemistry

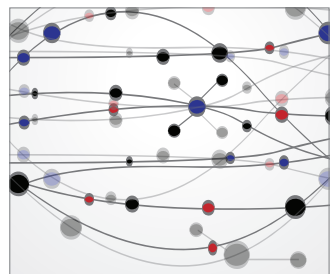

The Scientific World Journal
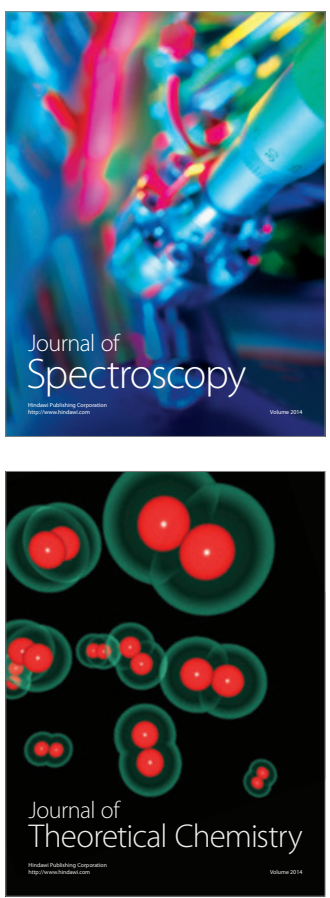
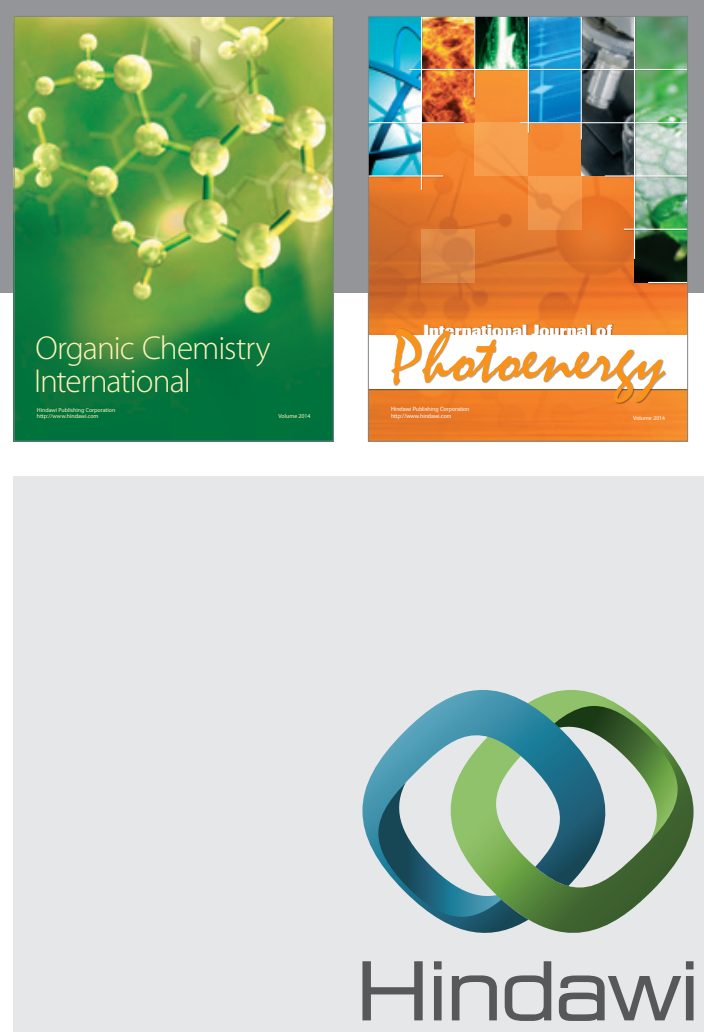

Submit your manuscripts at

http://www.hindawi.com

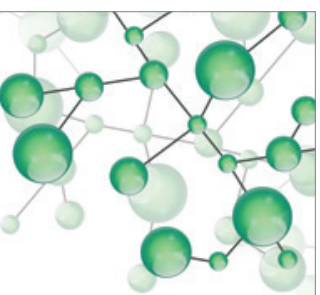

International Journal of

Inorganic Chemistry

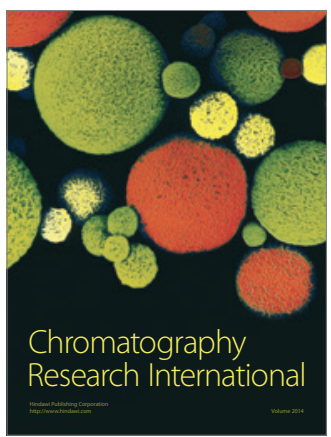

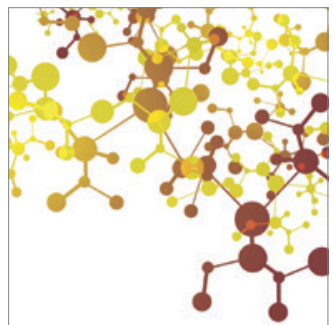

Applied Chemistry
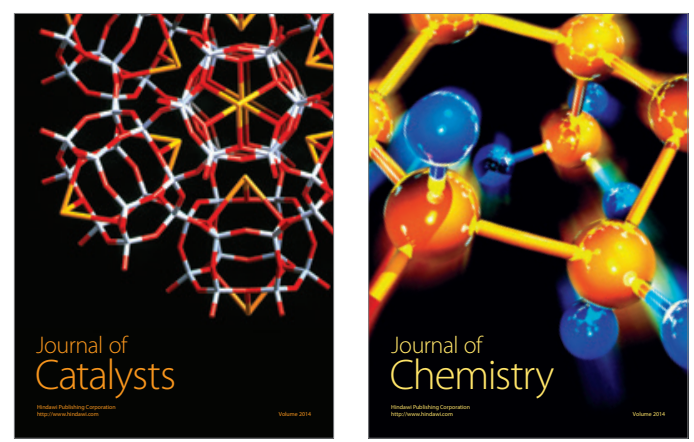
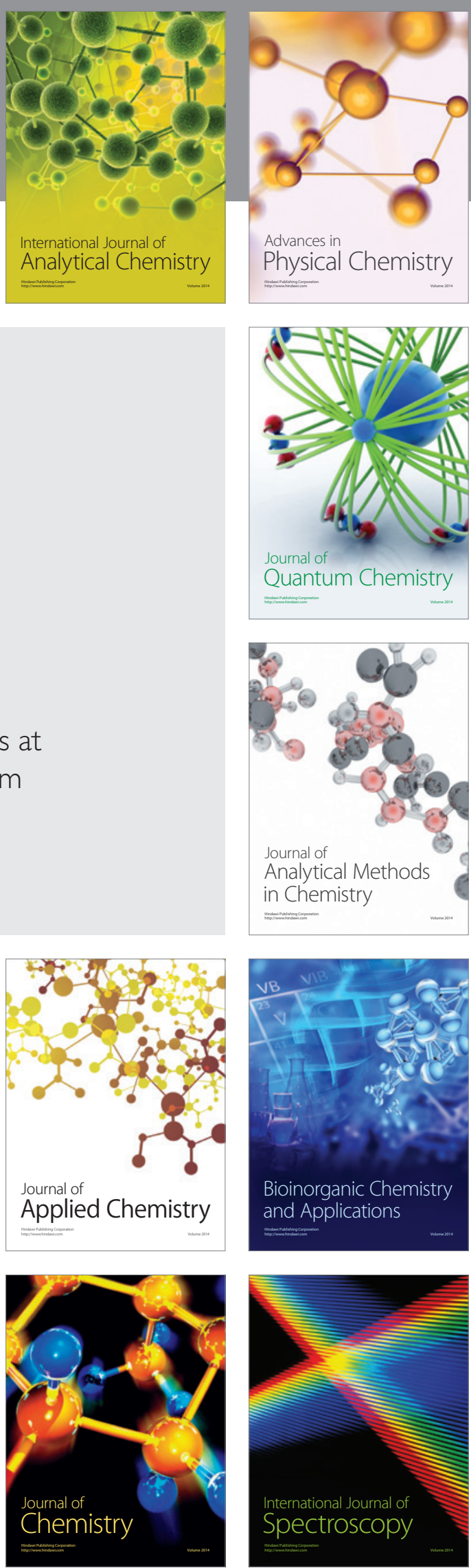